\title{
El principio de planeación en el contrato de obra pública*
}

\author{
María Camila Mesa Lozano** \\ Alfonso Muñoz Vargas***
}

Recibido: 12 de octubre de 2018 - Aprobado: 18 de enero de 2019

\section{Resumen}

Actualmente, se identifica una falta de planeación por parte de las entidades públicas en las obras que se realizan en el país, lo que ha generado incidencias como sobrecostos, retrasos en la entrega de obras, que se declare el contrato desierto y se genere una nulidad. De esta manera, se aborda la obra pública y su importancia, para posteriormente analizar las principales actuaciones por las cuales se vulnera el principio de planeación en los contratos de obra pública y, por último, elaborar las propuestas de desarrollo frente a las infracciones identificadas en los diferentes inconvenientes descritos. La metodología empleada para la elaboración de la presente investigación fue de tipo cualitativo, integrando la revisión documental de sentencias, decretos y leyes que permitieron el análisis de la vulneración en los contratos, y así llegar a una reflexión de tipo propuesta que describa la posibilidad de mitigar el impacto en la contratación centrado en el riesgo e interés general. Este artículo se origina a partir de la inquietud sobre las incidencias que tiene la falta

\footnotetext{
* Este artículo es producto del proyecto de investigación "El principio de planeación en el contrato de obra pública”, gestionado en la Especialización en Derecho Administrativo de la Universidad Libre de Bogotá. Citar como: Mesa Lozano, M. C. y Muñoz Vargas, A. (2019). El principio de planeación en el contrato de obra pública. Revista IUSTA, 51(2), 185-208. DOI: https://doi. org/10.15332/25005286.503

** Especialistas en Derecho Administrativo en la Universidad Libre, Bogota, Colombia. Agente de servicio al ciudadano Grado 2 de Colpensiones, Bogotá, Colombia. Orcid: https://orcid.org/00000002-6925-3930. Correo electrónico: cami01-02@hotmail.com

**** Especialistas en Derecho Administrativo en la Universidad Libre, Bogota, Colombia. Orcid: https:// orcid.org/0000-0002-6826-1130. Correo electrónico: alfomuva@gmail.com
} 
del principio de planeación en el contrato estatal de obra pública, para lo cual se plantearon como objetivos la naturaleza jurídica del principio de planeación en los contratos de obra pública, su importancia, las principales actuaciones por las cuales se vulnera y las propuestas frente a estas vulneraciones. La respuesta final que se obtuvo es la necesidad, por parte de las entidades públicas, de que se realicen unos estudios previos adecuados, y de esta manera evitar sobrecostos en la obra que se va a llevar a cabo. De igual manera, es importante que se realice y verifique el riego previsible y cuantificable, y así proteger el interés general.

Palabras clave: derecho administrativo, Administración pública, contratación pública.

\title{
The PRINCIPLE OF PLANNING IN THE PUBLIC WORKS CONTRACT
}

\begin{abstract}
Currently, a lack of planning by public entities is identified in the works carried out in the country, which has resulted in incidents such as overruns, delays in the delivery of works, declaring the contract deserted and a nullity is generated. Thus, the public work and its importance are addressed, to later analyze the main actions by which the principle of planning in the public works contracts is violated and, finally, to elaborate the proposals of development in view of the infractions identified in the different inconveniences described. The methodology used for the preparation of this research was qualitative, integrating the documentary review of judgments, decrees and laws that allowed the analysis of the violation in the contracts, and thus arrive to a reflection of a proposed type that describes the possibility of mitigating the impact on contracting focused on the risk and general interest. This article originates from the concern about the effects of the lack of the principle of planning in the public contract for public works, for which purpose the legal nature of the principle of planning in public works contracts, its importance, the main actions for which it is violated and the proposals against these violations are established as purposes. The final answer that was obtained is the need, by public entities, for adequate preliminary studies to be carried out, and thus avoid overruns in the work to be performed. Similarly, it is important that predictable and quantifiable risk are verified, and thus protect the general interest.
\end{abstract}

Keywords: Public administration, public procurement, administrative law. 


\section{O PRINCÍPIO DE PLANEJAMENTO NO CONTRATO DE OBRA PÚBLICA}

\section{Resumo}

Atualmente identifica-se uma falta de planejamento por parte das entidades públicas nas obras que realizam no país, o que tem gerado incidências como sobrecustos, atrasos na entrega de obras, que se declare o contrato deserto e se gere uma nulidade. Desta maneira, aborda-se a obra pública e sua importância, para de forma posterior analisar as principais atuações pelas quais se vulnera o princípio de planejamento nos contratos de obra pública e, por último, elaborar as propostas de desenvolvimento perante as infrações identificadas nos diferentes inconvenientes descritos. A metodologia utilizada para a elaboração desta pesquisa foi de tipo qualitativo, integrando a revisão documental de sentenças, decretos e leis que permitiram a análise da vulneração nos contratos, e assim chegar a uma reflexão de tipo proposta que descreva a possibilidade de mitigar o impacto na contratação focado no risco e interesse geral. Este artigo se origina a partir da inquietude sobre as incidências que tem a falta do princípio de planejamento no contrato estatal de obra pública, para o qual se apresentam como objetivos a natureza jurídica do princípio de planejamento nos contratos de obra pública, sua importância, as principais atuações pelas quais se vulnera e as propostas perante estas vulnerações. A resposta final que se obteve é a necessidade, por parte das entidades públicas, de que se realizem uns estudos prévios adequados e desta maneira evitar sobrecustos na obra que se realiza. Da mesma forma, é importante que se realizem e verifiquem o risco previsível e quantificável e assim proteger o interesse geral.

Palavras-chave: Administração pública, contratação pública, direito administrativo.

\section{Introducción}

El principio de planeación es el eje central para que el proceso de contratación estatal se desarrolle de una manera eficiente, desde la etapa precontractual hasta la liquidación del contrato, como se ha establecido en la Ley 80/1993, de 28 de octubre. Por ello, este artículo busca rescatar el valor supremo de este y su relevancia en el contrato de obra pública, para determinar qué incidencias tiene la falta del principio de planeación en el contrato estatal de obra pública. Con este fin, se detalla la importancia de este principio en el contrato de obra pública y se 
analizan las principales actuaciones, ya sea por acción, ya sea por omisión, por las cuales es vulnerado.

Uno de los obstáculos que ha tenido este principio para su ejecución en Colombia es que, además de la mención que se hace en la ley de contratación estatal, no ha tenido un amplio desarrollo normativo, razón por la cual las entidades públicas han dejado de lado este principio cuando realizan el plan anual de adquisiciones, lo que conlleva imprevistos en el desarrollo de la contratación de la obra pública debido a que se pueden presentar retrasos en la ejecución de la obra, sobrecostos como consecuencia de alzas en los precios de los materiales o incluso indemnizaciones millonarias a contratistas a causa de modificaciones unilaterales en los contratos.

Acorde con lo anterior, este trabajo se justifica en dar a conocer la necesidad de darle el carácter vinculante que tiene el principio de planeación en todo el proceso de contratación estatal con el fin de que se desarrolle el objeto del contrato. Este no es más que no afectar el interés general y para que este principio no se vea delimitado solo a los estudios previos que son desarrollados en la etapa precontractual, sino que se tenga como premisa en las demás etapas del proceso de la obra, que también requieren planeación y que son parte de la ejecución, el desarrollo y el cumplimiento de los términos contractuales.

\section{Naturaleza jurídica del principio de planeación en los contratos de obra pública}

A lo largo del tiempo, la palabra "principio" se ha entendido como un precepto, como el fin supremo que se desea alcanzar. Para Alexy, los principios son mandatos de optimización:

El carácter de los principios significa que no se trata simplemente de normas vagas, sino que con ellas se plantea una tarea de optimización. Dicha tarea es, en cuanto a la forma jurídica; en cuanto al fondo, sin embargo, es siempre también moral, a causa de su contenido moral. Puesto que algo análogo vale para muchos otros principios, la teoría de los principios ofrece un punto de partida adecuado para atacar la tesis positivista de la separación entre Derecho y moral. (1998, p. 144)

Por otra parte, para H. L. A. Hart los principios son generales o no específicos, se refieren más o menos explícitamente a algún propósito, meta, facultad o valor, 
son considerados, desde cierto punto de vista, como algo que resulta deseable preservar o ser objeto de adhesión, no solo suministran una explicación racional de las reglas que los ejemplifican, sino que al menos contribuyen a su justificación (Rodríguez, 1997).

El contrato de obra pública, por su parte, está definido como el contrato que celebran las entidades estatales para la construcción, el mantenimiento, la instalación y, en general, para la realización de cualquier otro trabajo material sobre bienes inmuebles, cualquiera que sea la modalidad de ejecución y pago (Agencia Nacional de Infraestructura, s. f.).

El principio de planeación en la contratación estatal en Colombia supone la debida planificación de un contrato en su etapa precontractual por parte de la entidad estatal.

La mayoría de los inconvenientes en los procesos de licitación de obras públicas se dan por falta de aplicación del principio de planeación. Se puede tomar como ejemplo los sobrecostos en las obras y la demora desmesurada en la entrega de dichas obras. El principio de planeación no está tipificado como tal, pues los principios que consagra la Ley 80/1993, de 28 de octubre son el de transparencia, el de economía y el de responsabilidad. Diferentes autores mencionan el principio de transparencia de la siguiente manera: "El principio de planeación es uno de los pilares en la actividad contractual, ya que el mismo debe obedecer a las necesidades reales de la comunidad, las cuales deben estudiarse, planearse y encontrarse debidamente presupuestadas por el Estado para cumplir con los fines estatales" (Sentencia 85001233100019960030901/2007, de 29 de agosto).

Asimismo, según Amaya,

el principio de planeación refiere a aquellas actividades encaminadas a determinar la necesidad que se pretende satisfacer de forma precisa, también establecer el objeto y los recursos con los cuales se ejecutará el contrato, lo anterior debe llevarse a cabo antes de dar inicio al proceso contractual, y de esta forma la administración da el correcto uso de los recursos. (2016)

De igual manera, las entidades estatales con la debida antelación a la apertura de un proceso contractual deben elaborar los respectivos estudios, diseños, proyectos y pliegos de condiciones según lo establecido en el Estatuto General de Contratación de la Administración pública, numeral 12, artículo 25, de la Ley 80/1993, de 
28 de octubre, modificado por el artículo 87 de la Ley 1474/2011, de 12 de julio (Matallana, 2013).

Si bien es cierto que el principio de planeación la Corte lo asocia a la etapa precontractual como lo hacen los otros jueces, entre ellos el Consejo de Estado, que parten de concebir que es en los estudios previos en los que se determina qué se puede contratar, señalando el objeto, y las obligaciones mutuas con base en la necesidad definida previamente, atendiendo las preguntas: ¿qué?, ¿̨por qué se necesita? y ¿̇cuánto cuesta? (Aponte, 2014, p. 196)

Entiéndase, entonces, que el principio de planeación responde claramente a la definición de principio como mandato optimizador del derecho (Bernal, 2005). Para este caso, se ha de comprender que es un deber que tiene a cargo la Administración pública para optimizar el ejercicio de esta misma.

A nivel normativo, el principio de planeación en los contratos de obra pública está dado como un principio innominado, toda vez que en la legislación colombiana taxativamente no se menciona el principio de planeación, sino que se encuentra inmerso en el desarrollo del proceso de contratación pública en general (Patarroyo y Benavides, 2014).

El principio de planeación se materializa de acuerdo con la siguiente normativa:

1. La Ley 80/1993, de 28 de octubre, por su parte, se caracterizó por ser una norma que innova en insertar principios en materia de contratación estatal, como el principio de transparencia que trae consigo la igualdad con la que deben contar todos los oferentes frente al proceso de selección en sí y esto se logra si desde el principio del proceso se tiene claridad frente a los requisitos habilitantes e instrumentos de escogencia con los que se elegirá la mejor propuesta para desarrollar el objeto del contrato y establece que "se definirán reglas objetivas, justas, claras y completas que permitan la confección de ofrecimientos de la misma índole, aseguren una escogencia objetiva y eviten las declaratorias de desierta de la licitación". Y esto se logra si se contó con una buena etapa de planeación que desarrollara de manera efectiva el análisis económico del sector y los estudios previos. A su vez, la norma habla del principio de economía, estableciendo que la maduración del proyecto, es decir, la etapa de planeación, solo se lleva a cabo si se tuvieron en cuenta todos los imprevistos que pueden afectar la ejecución del contrato y de esta manera blindar el proceso contractual frente a ellos (García y Fino, 2014). 
Por otra parte, en el artículo 4, numeral 8, nos habla de que es deber de la entidad "adoptar las medidas necesarias para mantener durante el desarrollo y ejecución del contrato las condiciones técnicas, económicas y financieras existentes en el momento de proponer en los casos en los que se hubiere realizado licitación, o de contratar en los casos de contratación directa". Por tanto, se deben adoptar en la etapa de planeación todas las medidas concernientes para evitar una posible paralización de la ejecución del contrato, como previniendo los posibles riesgos. De igual manera, la norma consagra como deber del contratista colaborar con las entidades contratantes en lo que sea necesario para que el objeto contratado se cumpla y que este sea de la mejor calidad. Para ello, por estar en cabeza de la entidad la dirección del contrato, se deben acatar las órdenes que durante el desarrollo del contrato les impartan y, de manera general, obrarán con lealtad y buena fe en las distintas etapas contractuales, por lo que evitarán las dilaciones y el entrabamiento que pudieran presentarse.

2. Ley 1150/2007, de 16 de julio, que modifica en apartes la Ley 80/1993, de 28 de octubre. Se establece en el artículo 3 que para el mejor funcionamiento y publicidad de los procesos de selección se habilita que en la etapa precontractual se emplee el medio electrónico: "La sustanciación de las actuaciones, la expedición de los actos administrativos, los documentos, contratos y en general los actos derivados de la actividad precontractual y contractual, podrán tener lugar por medios electrónicos". Asimismo, el pliego de condiciones debe establecer de una manera clara la distribución del riesgo en los contratos estatales, el cual es producto de la etapa de planeación.

En el artículo 8, se establece que "junto con los proyectos de pliegos de condiciones se publicarán los estudios y documentos previos que sirvieron de base para su elaboración", lo que deja entrever la relevancia que tiene la elaboración de la planeación de la contratación pública como base de la apertura del proceso de licitación.

3. La Ley 1882/2018, de 15 de enero, por su parte, modificó apartes de la Ley 1150/2007, de 16 de julio, en el sentido de establecer que, para la publicación del proyecto de pliego de condiciones y estudios previos, no es obligatorio por parte de la entidad contar con disponibilidad presupuestal para realizar la publicación del proyecto de pliego de condiciones, toda vez que esta disponibilidad presupuestal ya está inmersa en el Plan Anual de Adquisiciones por parte de las entidades estatales. 
De igual manera, el desarrollo jurisprudencial del principio de planeación en la contratación estatal ha establecido que la transgresión al principio de planeación en los contratos estatales determina la nulidad absoluta de un contrato, y para el manejo de los asuntos públicos y el cumplimiento de los fines estatales, debe existir un estricto orden para la adopción de las decisiones que efectivamente deban materializarse en favor de los intereses comunales (Sentencia 0174301/2013, de 24 de abril). De esta manera, el Consejo de Estado le da fuerza vinculante al principio de planeación en todo lo concerniente al contrato estatal.

En concordancia con lo anterior, la Sentencia 2012-00012/2015, de 10 de diciembre, en la decisión de una acción de controversias contractuales, considera que "el principio de planeación, cuya ausencia ataca la esencia misma del interés general, $[\ldots]$ [tiene] consecuencias gravosas y muchas veces nefastas, no solo para la realización efectiva de los objetos pactados, sino también para el patrimonio público, que en últimas es el que siempre está involucrado en todo contrato estatal”. De esta manera, sigue con la línea jurisprudencial de que la planeación del contrato estatal es la base de toda la actuación contractual, razón por la cual el desconocimiento de esta no permite la ejecución del objeto del contrato como fin de los fines del Estado.

A su vez, la Sentencia 0010100/2018, de 29 de enero ha establecido que

el principio de la planificación aplicado a los procesos de contratación y a las actuaciones relacionadas con los contratos del Estado guarda relación directa e inmediata con los principios de interés general y de legalidad, procurando incorporar en el régimen jurídico de los negocios del Estado el concepto según el cual la escogencia de contratistas, la celebración de contratos, la ejecución y liquidación de los mismos, no pueden ser, de ninguna manera, producto de la improvisación.

Por tanto, la ausencia de este vulnera la satisfacción del interés general como pilar de la contratación estatal.

\section{Importancia del principio de planeación en el contrato estatal de obra pública}

El principio de planeación es un elemento indispensable en la Administración pública, hace parte integral de las actividades que ejerce el Estado sobre la sociedad y es un principio que determina el éxito o fracaso que este puede tener en 
cualquier actividad que adelante. Asimismo, es una etapa del proceso de selección muy importante porque este principio genera optimización de los recursos públicos, agilidad en las contrataciones que desea adelantar cada entidad, adquisiciones inteligentes y eficientes. La falta de la aplicación de este abre la puerta al despilfarro de recursos del erario y al incumplimiento de las funciones y fines del Estado (Blanco y Leudo, 2016).

Con relación a este tema, Márquez (2007) indicó lo siguiente:

El papel preponderante de la nación, integrada al Estado, administración pública e instrumentos de la gestión pública y de ella se generan los instrumentos fundamentales de la gestión pública: Presupuestación y Planeación. Integrando estos elementos encontramos la contratación de la cual parte el sistema normativo de contratación estatal, indicando los subsistemas normativos que operan en el Estado colombiano. (Márquez, 2007, p. 104)

De igual manera, con el fin de que la contratación pública se emplee efectivamente como un instrumento de desarrollo y de aseguramiento de beneficios en interés general, el principio de planeación en la actividad contractual de las entidades estatales está relacionado con la oportunidad y conveniencia del contrato (Agencia Nacional de Infraestructura, s. f.). Por ello, deben elaborarse detalladamente los estudios y documentos soporte del proceso de selección, con el objetivo de lograr satisfacer la necesidad del servicio y la finalidad de la actividad de la entidad contratante (Millán, Blanco y Guecha, 2017).

La importancia del principio de planeación se ve reflejado como primera medida en el Plan Anual de Adquisiciones, que, acorde con lo establecido en el artículo 74 de la Ley 1474/2011, de 12 de julio, es el plan general de compras que debe realizar toda entidad con el fin de informar a la comunidad en qué es lo que invertirá el presupuesto anual aprobado en el plan de desarrollo. Este es el instrumento contractual con el que la entidad cuenta para adquirir bienes y servicios que necesita para el logro de los objetivos y de las metas institucionales que permitan el funcionamiento de la entidad durante una vigencia fiscal, y estos logros se evidencian con la realización de cada proyecto planificado, con miras al cumplimiento de los fines estatales.

En segundo lugar, es importante el principio de planeación para la elaboración del análisis económico del sector en los contratos de obra pública, ya que para la 
celebración del contrato es necesario que la entidad realice un análisis de costos, sin imprecisiones e improvisaciones en el momento de contratar, y evitar que la entidad genere sobrecostos.

El propósito de esta etapa es disminuir el riesgo de desvíos de fondos y de corrupción, sin embargo, se identifican casos, que, aunque tengan una planeación responsable, no tienen posibilidad de blindar el proceso de contratación del todo, y puede ser denegado en cualquier etapa, identificando entonces una mala práctica de contratación, que da lugar, en muchas ocasiones, a desfalcos de las entidades contratantes.

Según lo establecido en el Decreto 1082/2015, de 26 de mayo, artículo 2.2.1.1.1.6.1, "la obligación del análisis a cargo de la entidad, además es necesario para conocer el objeto del proceso de contratación desde la perspectiva legal, comercial, financiera, organizacional, técnica, y de análisis de Riesgo".

En tercer lugar, es importante precisar el objeto del contrato y permitir a los interesados diseñar sus ofertas y buscar diferentes fuentes de recursos para poder ejecutar la obra sin necesidad de generar sobrecostos (tiempo económico) favoreciendo a las dos partes del contrato.

Los contratos deben poseer estudios de prefactibilidad, factibilidad, ingeniería, suelos, necesidad, tipo de contrato, fundamento jurídico, modalidad de selección, costos o valor estimado, requisitos habilitantes, y señalar a quién le corresponde el riesgo. Se considera importante que en el contrato relacione las especificaciones de licencias, permisos y autorizaciones requeridas para la realización del contrato.

Asimismo, el cuarto aspecto de importancia del principio de planeación en el contrato de obra pública permite mejorar la administración de recursos estatales, a través de la planificación y codificación de las compras públicas como un tema estratégico para el correcto funcionamiento del Gobierno. En Colombia, se realiza mediante la Agencia Nacional de Contratación, Colombia Compra Eficiente, creada bajo el Decreto 4170/2011, de 3 de noviembre, que tiene como funciones la proposición de políticas públicas, planes, programas y normas en materia de compras y contratación pública, buscando criterios de racionalización normativa y la difusión de normas, reglas, procedimientos, medios tecnológicos y mejores prácticas para esta misma materia y de acuerdo con el cumplimiento de sus funciones.

En quinto lugar, con el principio de planeación, se puede determinar la viabilidad tanto económica como técnica de la posible obra por ejecutar, lo cual está íntimamente ligado con el principio de economía. Este último tiene por finalidad 
asegurar que todo proyecto esté antecedido de los estudios de orden técnico, financiero y jurídico, y así poder establecer la conveniencia o no para contratar; si resulta o no necesario celebrar el respectivo contrato de obra pública y su adecuación a los planes de inversión, de adquisición o compras, presupuesto y ley de apropiaciones, según el caso; y de ser necesario, deberá estar acompañado, además, de los diseños, los planos y las evaluaciones de prefactibilidad o factibilidad; las características que deba reunir el bien o servicio objeto de licitación pública de contrato de obra junto con los costos.

Ahora bien, la importancia del principio de planeación también se observa en la satisfacción del interés general, puesto que el contrato solo se debe celebrar cuando todos los factores están dados para que el objeto del contrato se desarrolle a cabalidad, y en caso de que se celebre sin la observancia de este, se viciaría de nulidad absoluta, por tanto, "se admite de manera unánime que el fundamento de la nulidad contractual descansa en la violación de la legalidad [...] que conlleva que el fin de la nulidad sea el restablecimiento de la legalidad violentada, eliminando la situación jurídica creada por la celebración del contrato” (Yong, 2013, pp. 237-238).

En concordancia con lo anterior, es posible remitirse al artículo 34, numeral 15 de la Ley 734/2002, de 5 de febrero, el cual establece que se deben ejercer las funciones consultando permanentemente los intereses del bien común, y teniendo siempre presente que los servicios que presta constituyen el reconocimiento y la efectividad de un derecho y buscan la satisfacción de las necesidades generales de todos los ciudadanos, y así establecer en la norma la facultad de sancionar a quien incurra en la intención de evadir su responsabilidad contractual con la inobservancia del principio de la planeación, y recordar que también agravaría a los civiles que cumplan funciones públicas como el contratista:

La ausencia de planeación ataca la esencia misma del interés general, con consecuencias gravosas y muchas veces nefastas, no solo para la realización efectiva de los objetos pactados, sino también respecto del patrimonio público, que en últimas es el que siempre está involucrado en todo contrato estatal, desconociendo en consecuencia fundamentales reglas y requisitos previos dentro de los procesos contractuales; es decir, en violación del principio de legalidad. (Santofimio, 2010, p. 412)

Por último, y no menos importante, implementar el principio de planeación y precaución en los contratos de obra pública le evita a la entidad contratante múltiples 
conflictos judiciales que interponga el contratista o terceros en contra del Estado como acciones de controversias contractuales o nulidad y restablecimiento del derecho buscando indemnizaciones o la ejecución del contrato, puesto que, si se tiene una correcta programación, elaboración, aprobación y ejecución de sus presupuestos, no da lugar a improvisaciones en ninguna de las etapas de la contratación (Sentencia 68001-23-15-000-1994-09826-01(28875)/2014, de 10 de septiembre).

En todos estos pasos, se puede evidenciar la importancia de la planeación, sobre todo en estos procesos de contratación de obra pública, ya que son de conocimiento general y cualquier persona puede estar pendiente de todo el proceso como veedores ciudadanos, con el fin de evaluar la gestión de la Administración pública y asimismo de los servidores públicos.

\section{Principales actuaciones que vulneran el principio de planeación en el contrato de obra pública}

El principio de planeación en los contratos de obra pública se ha caracterizado por ser el pilar de la contratación misma, por cuanto es el punto de partida en lo que concierne a cuál es la necesidad que se pretende satisfacer, el objeto a contratar y los recursos para ejecutar el contrato. Por ello, por la misma relevancia que trae consigo, es igual de susceptible de ser vulnerado como en los casos que se describen.

\section{Falta de elaboración de estudios previos}

En la práctica, una de las principales omisiones por las cuales se vulnera este principio ocurre cuando no se hacen adecuadamente los estudios previos, los cuales están en cabeza de la Administración pública, que corresponde con los deberes que tiene el Estado relacionados con una correcta administración de los recursos públicos y el buen desempeño de las funciones públicas (Sentencia 11001-24715/2007), la ausencia o insuficiencia de estudios previos, permisos o licencias o evaluaciones sobre estos, que hagan factible la ejecución del objeto del contrato. Esto conlleva el detrimento del erario público y da lugar a la malformación del contrato y a la esencia misma de la contratación estatal.

De igual manera, al celebrar un contrato estatal, en especial el de obra pública con el desconocimiento del principio de la planeación, se está viciando el contrato por objeto ilícito, como nulidad del contrato, toda vez que se considera que hay en 
general objeto ilícito en todo acto o contrato prohibido por la ley (Claro, 1979). Lo anterior también ratificado por el Código Civil en el artículo 1519 que habla sobre el objeto ilícito estableciendo que hay un objeto ilícito en todo lo que contraviene al derecho público de la nación (Ley 84/1873, de 26 de mayo, Código Civil de los Estados Unidos de Colombia); por esto, se afectaría la delimitación, eficacia y eficiencia del contrato que se va a desarrollar (Young, 2013).

\section{No se hace la correcta previsión del riesgo}

Otra de las causales por las cuales se vulnera el principio de planeación ocurre cuando no se hace una correcta previsión del riesgo en la parte económica de los contratos de obra pública, que en la mayoría de los casos se presenta cuando en el Plan Anual de Adquisiciones no se tiene en cuenta la variación en la tasa de cambio, ni de los insumos necesarios para la ejecución de la obra, lo que conlleva el retardo en los pagos por parte de la entidad pública al contratista y que este a su vez presente iliquidez financiera en su organización (Díaz y Riaño, 2012).

Como consecuencia de lo anterior, se puede dar la ruptura del equilibrio económico del contrato (Contraloría General de la República, 2013). Por lo general, con la teoría del hecho del príncipe (Sentencia 250002326000199704638012068 $3 / 2011$, de 7 de marzo) o en los casos en que se presentan sobrecostos que pueden provenir de actos o hechos imputables a la Administración. Esto se da, en general, cuando no se contemplan de una manera adecuada los costos directos del contrato, como materiales, mano de obra, equipo, entre otros, y los costos indirectos que son los de administración, imprevistos y utilidad (Rojas, Acevedo y Jiménez, 2017).

Ahora bien, en los casos en los que no se acuerda las prestaciones específicas a cargo de las partes como criterio objetivo de la futura obra, se ve afectado el principio de planeación, puesto que posteriormente se puede iniciar la acción de controversias contractuales en contra de la entidad como consecuencia de discrepancias en la interpretación de las obligaciones contractuales.

\section{Transgresión de la libre competencia}

Otro factor determinante que atenta contra el principio de planeación es la competencia desleal frente al mercado de la oferta y la demanda, que muta en monopolios de contratistas que son los únicos facultados para ofrecer un determinado producto o servicio y que malforma los pliegos de condiciones en pliegos sastre 
hechos a la medida con características que solo puede cumplir determinado oferente. En concordancia con lo anterior, también se puede presentar la competencia desleal cuando no se realiza la selección objetiva del contratista, sino por el contrario cuando se escoge acudiendo a criterios de conveniencia y de intereses particulares.

En este mismos aspecto, se puede infringir el principio de planeación cuando se celebran contratos interadministrativos sin el lleno de los requisitos legales, pues, si bien es cierto que el literal c del numeral 1 del artículo 24 de la Ley 80/1993, de 28 de octubre autoriza a las autoridades públicas de todos los niveles para suscribir directamente convenios interadministrativos (Sentencia 202622017/2017, de 30 de noviembre), también es cierto que no lo pueden hacer sin la convocatoria a otros oferentes, debido a que el contrato se debe ceñir a los principios de oportunidad y conveniencia, rectores de la planeación del contrato.

Por otra parte, cuando se desconoce el principio de publicidad, también se atenta contra el principio de planeación, puesto que, si no se coloca a disposición de los administrados las actuaciones de la Administración (Sentencia 81001233300020120004301 (249614)/2016, de 2 de junio de 2016), no se garantiza la participación de todos los que se encuentren interesados.

No se tienen en cuenta las características particulares de la futura obra

El principio de planeación también puede ser vulnerado si la entidad contratante no contempla el Plan de Ordenamiento Territorial (POT), toda vez que, si no se cuenta con los permisos de orden urbanístico y de planeación frente a las reglas y limitaciones para el uso del suelo de cada municipio (Becerra, 2008), difícilmente se puede ejecutar la obra.

\section{Propuesta frente a las vulneraciones del principio de planeación en el contrato de obra pública}

Una de las maneras de blindar la futura licitación es realizando unos adecuados estudios previos que, entre otros fines, persiguen cumplir con la obligación de establecer los precios reales del mercado de aquellas cosas o servicios que serán objeto del contrato que pretende celebrar la Administración, de tal suerte que pueda tener un marco de referencia que le permita evaluar objetivamente las propuestas que se 
presenten durante el respectivo proceso de escogencia del contratista (Sentencia 73001-23-31-000-1999-00536-01(22471)/2012, de 28 de marzo).

Asimismo, frente a los sobrecostos en el contrato, es necesario que la entidad en los pliegos de condiciones suprima al máximo el margen de error, como en los casos en que se evidencien yerros en los precios que se establecieron en la licitación. El contratista puede asumir dos posturas:

a) suscribir el contrato, pero con precios de mercado adecuados, es decir, renegociando el valor unitario de los ítems — en otras palabras, debió pedir la revisión del precio-, o b) desistir del negocio, porque no satisfacía su pretensión económica, teniendo en cuenta que estaba vigente un impuesto que gravaba la actividad adicional que pretendía ejecutar. (Sentencia 2500023310002000130180116653/2009, de 11 de febrero)

En concordancia con lo anterior, es necesario detectar posibles fallas dentro de los procedimientos que se estén realizando o que se planee realizar en la contratación de la obra pública, así como desviaciones o irregularidades que puedan llevar a retrasos e inconformidades, efectuando correctivos y mejoras inmediatas y oportunas para el adecuado alcance de los objetivos. Así, se ha de identificar este control de advertencia desde el punto de vista del principio de planeación.

Por otra parte, es de relevancia que la entidad en el momento de realizar el análisis y la estimación del riesgo verifique la identificación, previsibilidad, cuantificación o la distribución del riesgo. Para ello, hay diversos medios de cobertura, y uno de los más importantes que debe tener en cuenta la entidad, y así lo ha mencionado la Sentencia C-648/2002, de 13 de agosto, es el de la garantía, que constituye entonces la protección del interés general, en la medida en que permite resarcir el detrimento patrimonial que se ocasione al patrimonio público por el incumplimiento de las obligaciones adquiridas por el contratista. Asimismo, el principal mecanismo que la ley consagra para garantizar el equilibrio económico del contrato es la revisión o reajuste de precios, el cual permite que se produzca un ajuste positivo o negativo en el precio frente a la ocurrencia de cambios en las condiciones de ejecución contractual (Leudo y Blanco, 2016).

En consecuencia, para mitigar el riesgo económico inmerso en la ejecución del contrato de obra pública, se deben realizar "los análisis a partir de los cuales se identifiquen los amparos, porcentajes y vigencias que deban ser cobijados por 
las garantías que soliciten a sus contratistas y la implementación de acciones para asegurar que las condiciones de suficiencia de las mismas permanezcan incólumes en los términos consagrados en la ley" (Veeduría Distrital de Bogotá, 2012). De igual manera, se debe realizar un plan de contingencia en caso de entrega tardía de predios, o cuando exista disputa sobre estos, con el fin de que no ocurran retrasos en la ejecución de la obra que afecten el interés general.

Ahora bien, para evitar la competencia desleal, en concordancia con el principio de igualdad que debe primar sobre la contratación estatal en general, se debe garantizar un trato igualitario a todos los oferentes tanto en la exigencia de los requisitos previstos en el pliego de condiciones como en la calificación de sus ofertas y, por supuesto, en la selección de aquella que resulte más favorable para los intereses de la Administración (Llano, 2013).

En consecuencia, con el propósito de prevenir el riesgo, actualmente las entidades públicas en Colombia cuentan con una plataforma implementada por Colombia Compra Eficiente, que es un manual para la identificación y cobertura del riesgo en los procesos de contratación que permite minimizar los imprevistos derivados de aspectos tales como geológicos, presencia de redes y servicios públicos, costos de operación, financiación del contratista, entre otros.

En concordancia con lo anterior, también se pueden consultar las bases de datos del Registro Único de Precios de Referencia (PURF) del Sistema de Información para la Vigilancia de la Contratación Estatal (SICE) según el Decreto 3512/2003, de 5 de diciembre y el Decreto 2474/2008, de 7 de julio y la Ley 598/2000, de 18 de julio, debido a que los precios cotizados no deben sobrepasar ni estar por debajo del precio indicativo del bien o servicio, registrado en el sistema de información para la vigilancia de la contratación estatal.

De igual manera, en la etapa de la planeación en el contrato de obra pública, es de vital importancia realizar la evaluación de la experiencia requerida para la ejecución de la obra de manera objetiva. En caso de que esta no se realice o se lleve a cabo mediocremente, se atenta contra la estabilidad del contrato, puesto que, si se escoge al contratista que no tenga la experiencia ni la liquidez adecuada para la ejecución de la obra, se empezarán a presentar retrasos que vulneran uno de los aspectos por los cuales se llevó a cabo, que es la necesidad de la obra para satisfacer el interés general y así evitar retrasos en la ejecución de la obra, puesto que la experiencia del contratista debe ser proporcional a la naturaleza del contrato y su 
valor (Sentencia C-713/2009, de 7 de octubre). Esto significa que los criterios para la escogencia del contratista deben estar dotados de objetividad e imparcialidad.

Por su parte, en el artículo 2 de la Ley 80/1993, de 28 de octubre, se establece que el deber de planeación también debe ser garantizado también por los particulares, puesto que son los que colaboran con la entidad dentro de la ejecución contractual y tienen la obligación de detectar y corregir los yerros que se puedan presentar en la futura contratación. Pero además la ley les impone el deber de evitar participar en procesos de contratación en los que se evidencie el desconocimiento de tal deber (Departamento Nacional de Planeación [DNP], 2004), con el fin de evitar la nulidad absoluta del contrato por objeto ilícito.

\section{Conclusiones}

Con la presente investigación acerca de las incidencias que tiene la falta del principio de planeación en el contrato de obra pública, se logró concluir que, a pesar de que los principios son mandatos de optimización en Colombia, el principio de planeación en la contratación estatal no está reglado normativamente, puesto que en la Ley 80/1993, de 28 de octubre no se encuentra tipificado, y así le resta relevancia y su carácter vinculante en todo el proceso contractual.

La celebración de contratos de obra pública tiene un fin altruista que es la satisfacción del interés general, mediante la construcción, el mantenimiento o la instalación de mano de obra sobre bienes inmuebles, por tanto, en los casos en los que se presentan anomalías que afecten el plazo establecido para la ejecución de la obra o el precio pactado, se atenta directamente contra el bienestar común.

El principio de planeación debe desarrollarse bajo valores axiológicos, como la responsabilidad, transparencia e idoneidad, como consecuencia de la importancia que tiene para el Estado administrar de una manera adecuada los recursos del erario público y el cumplimiento de los fines estatales.

La etapa de maduración del proyecto es conocida como la etapa precontractual, es decir, la de planeación, pero la doctrina ha venido desarrollando la tesis de que el principio de planeación, no solo se puede limitar a esta etapa, sino que debe estar inmerso en todas las etapas del contrato para que se desarrolle su objeto.

Para que los fines del Estado se desarrollen de manera exitosa mediante la contratación de obras públicas, es necesaria la participación eficiente, no solo de la entidad contratante, sino de la cooperación activa por parte del contratista, que 
en el desarrollo del principio de planeación es un veedor de la actividad contractual, y en caso de inconformidad frente a los pliegos de condiciones, puede advertir a la entidad sobre presuntas irregularidades, a su vez, es quien debe ejecutar el contrato dentro del plazo acordado.

En los casos en los que se celebra contrato de obra pública con el desconocimiento del principio de planeación, se está viciando el contrato por objeto ilícito, lo que desencadena la nulidad absoluta del contrato, toda vez que, si se realiza la contratación con el desconocimiento de este principio, se estaría en contra del interés general, $\mathrm{y}$ esto es prohibido por la norma.

Para evitar malversación de los recursos del Tesoro Público en concordancia con el principio de planeación, es necesario realizar la correcta previsión del riesgo que no puede dar lugar a improvisaciones, para que la entidad pague el precio justo por los materiales e insumos de la futura contratación y, a su vez, para que no asuma cancelaciones de indemnizaciones millonarias al contratista que proviene de la ruptura del equilibrio económico del contrato como consecuencia de la paralización de la obra por causas imputables a la entidad.

Los procesos de selección de los contratistas en los contratos de obra pública deben estar blindados de objetividad y transparencia, con el fin de evitar el fenómeno de la competencia desleal, puesto que se debe seleccionar al que cumpla de una mejor manera con los requisitos de experiencia, conveniencia, liquidez y confiabilidad, para garantizar el bienestar común.

El principio de planeación es necesario para que la Administración tenga éxito en las actividades que adelanta, como el contrato de obra pública, que se efectúan con eficacia y eficiencia preservando los recursos públicos. Una mala planificación genera el fracaso, el despilfarro de recursos del erario y el incumplimiento de las funciones y los fines del Estado.

Para mejorar la planeación frente a los sobrecostos en el contrato, es necesario que la entidad en los pliegos de condiciones suprima al máximo el margen de error, para ello puede suscribir el contrato, pero con precios de mercado adecuados, es decir, renegociando el valor unitario y desistir del negocio si no satisface su pretensión económica.

Es necesario detectar posibles fallas dentro de los procedimientos que se estén realizando en la contratación de la obra pública, así como desviaciones o irregularidades que puedan llevar a retrasos e inconformidades, efectuando correctivos y mejoras inmediatas y oportunas para el adecuado alcance de los objetivos; es 
preciso entonces identificar este control de advertencia desde el punto de vista del principio de planeación.

Con el propósito de prevenir el riesgo, actualmente las entidades públicas en Colombia cuentan con una plataforma implementada por Colombia Compra Eficiente, que es un manual para la identificación y cobertura del riesgo en los procesos de contratación que permite minimizar los imprevistos derivados de aspectos tales como geológicos, presencia de redes y servicios públicos, costos de operación, financiación del contratista, etc.

También es necesario que los funcionarios consulten las bases de dados del PURF del SICE para evitar que los precios no sobrepasen este valor o lo superen en el momento de realizar la cotización.

\section{Referencias}

Agencia Nacional de Infraestructura (s. f.). Abcé de la ANI. Recuperado de https://www.ani. gov.co/basic-page/abcs-de-la-ani-21806

Alexy, R. (1988). Sistema jurídico, principios jurídicos y razón práctica. Trabajo presentado en IV Jornadas Internacionales de Lógica e Informática Jurídicas, San Sebastián, España. Recuperado de https://rua.ua.es/dspace/bitstream/10045/10871/1/Doxa5_07.pdf

Amaya Rodríguez, C. F. (2016). El principio de planeación en la contratación estatal, un principio no tipificado. Revista Via Iuris, 20, 105-119.

Amaya, L. (2016). La violación al principio de la planeación en la contratación estatal: el cambio jurisprudencial y los efectos adversos que se desprenden de la nueva postura. Nova et Vetera, 2(16). Recuperado de http://www.urosario.edu.co/revista-nova-et-vetera/ Inicio/Omnia/La-violacion-al-principio-de-la-planeacion-en-la-c/

Aponte Díaz, I. (2014). Fallas de planeación y su incidencia en el contrato estatal de obra. Revista Digital de Derecho Administrativo, 11, 177-207. Recuperado de https://revistas. uexternado.edu.co/index.php/Deradm/article/view/3831

Becerra Salazar, Á. D. (2008). Los riesgos en la contratación estatal: estimación, tipificación y asignación. Bogotá, Colombia: Leyer. 
Bernal Pulido, C. (2005). El derecho de los derechos: escritos sobre la aplicación de los derechos fundamentales. Bogotá, Colombia: Universidad Externado de Colombia.

Circular 006/2012, de 24 de enero, lineamientos generales de la gestión contractual.

Claro Solar, L. (1979). Explicaciones de derecho civil chileno y comparado. Tomo VI: De las obligaciones. Santiago de Chile, Chile: Editorial Jurídica de Chile.

Contraloría General de Colombia. (2003). Contratación estatal. Bogotá, Colombia: Autor. Recuperado de https://www.procuraduria.gov.co/relatoria/media/file/flas_juridico/717_CGR-Concepto\%20157156-2013.pdf

Decreto 3512/2003, de 5 de diciembre, por el cual se reglamenta la organización, funcionamiento y operación del Sistema de Información para la Vigilancia de la Contratación Estatal, SICE, creado mediante la Ley 598 de 2000, y se dictan otras disposiciones.

Decreto 2474/2008, de 7 de julio, por el cual se reglamentan parcialmente la Ley 80 de 1993 y la Ley 1150 de 2007 sobre las modalidades de selección, publicidad, selección objetiva, y se dictan otras disposiciones.

Decreto 4170/2011, de 3 de noviembre, por el cual se crea la Agencia Nacional de Contratación Pública - Colombia Compra Eficiente-, se determinan sus objetivos y estructura.

Decreto 1082/2015, de 26 de mayo, por medio del cual se expide el Decreto Único Reglamentario del sector Administrativo de Planeación Nacional.

Departamento Nacional de Planeación. (2004). Manual de buenas prácticas para la gestión contractual pública. Bogotá, Colombia: Autor. Recuperado de https://www.ramajudicial. gov.co/documents/3272611/3370501/MANUAL_BUENAS_PRACTICAS+DNP. pdf/c97d8bdb-444a-405e-8aac-e42745af2e04

Díaz Hernández, M. del C. y Riaño González, M. A. (2012). El riesgo en el contrato de obra (Trabajo de especialización, en Derecho Administrativo, Universidad Militar Nueva Granada, Bogotá, Colombia).

Expediente 80112-EE157156/2013, de 2 de diciembre, contratación estatal. 
García Garzón, M. G. y Fino, G. (2014). Los impuestos territoriales en Colombia y la inequidad social: ¿la voluntad de la clase dominante erigida en ley? Revista IUSTA, 41(2), 61-75. https://doi.org/10.15332/s1900-0448.2014.0041.04

Leudo Paz, H. R. y Blanco Alvarado, R. C. (2016). Renegociación de contratos de concesión vial. Revista Republicana, 19, 71-192.

Ley 80/1993, de 28 de octubre, por la cual se expide el Estatuto General de Contratación de la Administración pública.

Ley 84/1873, de 26 de mayo, Código Civil de los Estados Unidos de Colombia.

Ley 598/2000, de 18 de julio, por la cual se crean el Sistema de Información para la Vigilancia de la Contratación Estatal, SICE, el Catálogo Único de Bienes y Servicios, CUBS, y el Registro Único de Precios de Referencia, RUPR, de los bienes y servicios de uso común en la Administración pública y se dictan otras disposiciones.

Ley 734/2002, de 5 de febrero, por la cual se expide el Código Disciplinario Único.

Ley 1150/2007, de 16 de julio, por medio de la cual se introducen medidas para la eficiencia y la transparencia en la Ley 80/1993, de 28 de octubre y se dictan otras disposiciones generales sobre la contratación con recursos públicos.

Ley 1474/2011, de 12 de julio, por la cual se dictan normas orientadas a fortalecer los mecanismos de prevención, investigación y sanción de actos de corrupción y la efectividad del control de la gestión pública.

Ley 1882/2018, de 15 de enero, por la cual se adicionan, modifican y dictan disposiciones orientadas a fortalecer la Contratación Pública en Colombia, la ley de infraestructura y se dictan otras disposiciones.

Llano, J. V. (2013). Prácticas jurídicas locales desde los actores del conflicto armado en Colombia. IUSTA, 2(39), 257-287. https://doi.org/10.15332/s1900-0448.2013.0039.01

Márquez Buitrago, O. (2007). La nueva gestión pública contractual: del contrato estatal de Ley 80/1993, de 28 de octubre al instrumento de gestión pública de Ley 1150/2007, de 16 de julio. Jurídicas, 4(2), 95-125. 
Matallana Camacho, E. (2013). Manual de contratación de la Administración pública. Bogotá, Colombia: Universidad Externado de Colombia.

Millán Durán, J., Blanco Alvarado, C. y Guecha Medina, C. N. (2017). Los procesos de selección de operadores privados del servicio público de televisión en torno a la libre concurrencia. En AA. VV, Justicia Constitucional. Tomo II (pp. 199-220). Bogotá, Colombia: Ibáñez.

Patarroyo Rengifo, S. y Benavides Gómez, P. A. (2014). Rupturas asignificantes: revisiones críticas en torno al derecho. Via Inveniendi et Iudicandi, 9(1), 7-31. https://doi. org/10.15332/19090528

Programa de las Naciones Unidas para el Desarrollo. (2011). Buenas prácticas de transparencia en la gestión contractual. Bogotá, Colombia: Autor. Recuperado de http://www.co.undp. org/content/colombia/es/home/library/democratic_governance/buenas-practicas-detransparencia-en-la-gestion-contractual.html

Rodríguez, C. (1997). La decisión judicial: el debate Hart-Dworkin. Bogotá, Colombia: Siglo del Hombre.

Rojas, M., Acevedo, N. y Jiménez, L. (2017). Propuesta de modificación financiera para el proceso de contratación estatal: caso aplicado. Revista Espacios, 38(53). Recuperado de http://www.revistaespacios.com/a17v38n53/a17v38n53p02.pdf.

Romero, F. (2013). El cartel de la contratación: la historia no revelada. Bogotá, Colombia: Ediciones B.

Santofimio Gamboa, J. O. (2010). El contrato de concesión de servicios: coherencia con los postulados del Estado social y democrático de derecho en aras de su estructuración en función de los intereses públicos (Tesis doctoral, Universidad Carlos III, Madrid, España).

Sentencia C-648/2002, de 13 de agosto, proceso de responsabilidad fiscal de contraloría.

Sentencia 85001233100019960030901/2007, de 29 de agosto. 
Sentencia 24715/2007, de 3 de diciembre, acción de nulidad en contra del Decreto 2170 de 30 de septiembre de 2002.

Sentencia 11001-24715/2007.

Sentencia 2500023310002000130180116653/2009, de 11 de febrero.

Sentencia C-713/2009, de 7 de octubre, acción pública de inconstitucionalidad.

Sentencia 2500023260001997046380120683/2011, de 7 de marzo.

Sentencia 73001-23-31-000-1999-00536-01(22471)/2012, de 28 de marzo.

Sentencia 7300123310001999005360122471/2012, de 28 de marzo.

Sentencia 0174301/2013, de 24 de abril.

Sentencia 68001-23-15-000-1994-09826-01(28875)/2014, de 10 de septiembre, contrato estatal.

Sentencia C-499/2015, de 5 de agosto, disposiciones para prevenir y combatir la corrupción en la contratación pública.

Sentencia 05001-23-33-000-2002-003682 01/2015, de 10 de diciembre, acción de reparación directa.

Sentencia 2012-00012/2015, de 10 de diciembre, municipio.

Sentencia 81001233300020120004301 (249614)/2016, de 2 de junio de 2016.

Sentencia 202622017/2017, de 30 de noviembre.

Sentencia 0010100/2018, de 29 de enero.

Sentencia 2016-00054/2018, de 29 de enero, acción de nulidad y restablecimiento del derecho. 
Veeduría Distrital de Bogotá. (2012). Lineamientos generales de la gestión contractual. Bogotá, Colombia: Autor. Recuperado de http:/www.veeduriadistrital.gov.co/transparencia/ marco-legal/Lineamientos/Circular-006-2012

Yung, S. (2013). El contrato estatal en el contexto de la nueva legislación. Bogotá, Colombia: Ibáñez. 